\title{
Rancang Bangun Sistem Informasi Pendataan Pasien Rawat Inap Berbasis Web
}

\author{
Erna Astiyani ${ }^{1}$, Jihan Fahira ${ }^{2}$, Dionysius Fajar Wicaksono ${ }^{3}$ \\ ${ }^{1,2}$ Program Studi Sistem Informasi Universitas Raharja, ${ }^{3}$ Program Studi Teknik Informatika \\ Universitas Raharja \\ Email : ${ }^{1}$ erna.astriyani@ raharja.info, *23ihan.fahira@ raharja.info, ${ }^{3}$ Dionysius@ raharja.info
}

\begin{abstract}
Abstrak
Komputer adalah sebuah alat yang membantu dalam mengakses informasi tersebut. Dalam hal ini setiap individu, perusahaan, dan instansi yang menggunakan trend teknologi harus mampu mengembangkan sistem yang telah mereka gunakan, sehingga tidak lagi tertinggal pada era mendatang, karena teknologi selalu diperbarui setiap saat. Sistem pengolahan data pelayanan pada Rumah Sakit Sitanala pada saat ini masih secara manual, sehingga pasien harus menunggu cukup lama jika berobat. Belum adanya prosedur pelayanan secara terkomputerisasi dalam pengolahan data pasien, sehingga mengakibatkan data tercecer dan mudah hilang. Hal tersebut menunjukan bahwa peranan sitem pelayanan pada suatu perusahaan sangat penting. Membuatkan sistem yang terkomputerisasi untuk sistem pendataan pasien rawat inap, untuk mendapatkan informasi yang akurat, cepat dan tepat. Sistem yang diusulkan nantinya akan menampilkan menu input data mulai dari pasien masuk ruang rawat inap, hasil diagnosa pasien, tindakan yang didapat selama dirawat, kamar pasien sampai tanggal pasien keluar serta sebagai metode laporan pendataan pasien perbulan sampai pertahun untuk laporan pimpinan. Metode yang digunakan adalah metode analisis data deskriptif. Teknik pengumpulan data, dengan melakukan observasi ke perusahaan, melakukan wawancara, dan melakukan studi pustaka dengan buku-buku, literature, bahan-bahan yang didapat selama perkuliahan yang relevan dengan permasalahan yang diteliti. Sedangkan untuk menganalisa penelitian ini menggunakan Unified Modelling Language (UML) untuk menggambarkan prosedur dan proses yang berjalan saat ini.
\end{abstract}

Kata Kunci : Komputer, Pasien Rawat Inap, Sistem Informasi, Pendataan.

\begin{abstract}
The computer is a tool that helps the information. In this case every individual, company, and institution that uses technology trends must develop the system that they have used, so that they are no longer out of date, because technology is always updated all the time. The service data processing system at Sitanala Hospital is currently still manual, so patients must wait long enough for treatment. There is no computerized treatment procedure in processing patient data, so data is scattered and easily lost. This shows the role of the system in the company is very important. Creating a computerized system for inpatient data collection systems, to get accurate, fast and precise information. The proposed system will display a menu of input data ranging from patients entering the inpatient room, the results of patient diagnoses, actions taken when translating, patient rooms until the date of the patient's discharge as well as a method of reporting patient data monthly to annual for the leadership discovery. The method used is descriptive data analysis method. The technique of collecting data, by making observations to the company, conducting interviews, and conducting library studies with books, literature, materials obtained during lectures relevant to the experience gained. Meanwhile, to analyze this research, it uses Unified Modeling Language (UML) to discuss the procedures and processes that are currently running.
\end{abstract}


Keywords: Computers, Inpatients, Information Systems, Data Collection.

\section{Pendahuluan}

Perkembangan teknologi informasi di era globalisasi ini semakin pesat dan memberikan pengaruh yang sangat besar terhadap keberlangsungan hidup manusia, sehingga perkembangan teknologi saat ini dapat mempermudah perkerjaan sehari-hari di segala kalangan mulai dari individu, sampai pada perusahaan serta instansi pemerintahan. Tidak hanya perkembangan ilmu pengetahuan, teknologi juga semakin pesat, khususnya ilmu komputer. Dalam hal ini setiap individu, perusahaan, dan instansi yang menggunakan trend teknologi harus mampu mengembangkan sistem yang telah mereka gunakan, sehingga tidak lagi tertinggal pada era mendatang, karena teknologi selalu diperbarui setiap saat.

Sistem pengolahan data pasien rawat inap pada Rumah Sakit Sitanala pada saat ini masih secara manual, tidak adanya prosedur pendataan secara terkomputerisasi dalam pengolahan data pasien rawat inap, mengakibatkan data mudah hilang dan keterlambatan pengolahan laporan untuk pimpinan. Hal tersebut menunjukan bahwa peranan sistem pendataan data pasien rawat inap pada suatu rumah sakit sangat penting. Membuatkan sistem yang terkomputerisasi untuk sistem pendataan pasien rawat inap, untuk mendapatkan informasi yang akurat, cepat dan tepat. Sistem yang diusulkan nantinya akan menampilkan menu input data mulai dari pasien masuk ruang rawat inap, hasil diagnosa pasien, tindakan yang didapat selama dirawat, kamar pasien sampai tanggal pasien keluar serta sebagai metode laporan pendataan pasien perbulan sampai pertahun untuk laporan pimpinan.

\section{Metode Penelitian}

Metode penelitian merupakan suatu tata cara atau kegiatan pelaksanaan penelitian rangka untuk mengumpulkan informasi atau data serta melakukan investigasi terhadap data yang telah didapatkan tersebut. yang didasari oleh asumsi-asumsi dasar, pandangan-pandangan filosofis dan ideologis, pertanyaan dan isu-isu yang dihadapi. Suatu penelitian mempunyai rancangan penelitian tertentu. Rancangan ini menggambarkan prosedur atau langkah-langkah yang harus ditempuh, waktu penelitian, sumber data dan kondisi arti untuk apa data dikumpulkan dan dengan cara bagaimana data tersebut dihimpun dan diolah untuk dianalisa dalam pembuatan laporan.

\subsection{Metode Observasi (Observasi Research)}

Pada tahapan ini penulis melakukan pengamatan langsung dari rumah sakit sitanala untuk mendapatkan data dan informasi yang akurat dan lengkap dari berbagai pihak yang terkait dan berhubungan dengan tema penelitian yang berhasil penulis rumuskan.

\subsection{Metode Wawancara (Interview Research)}

Pada metode ini penulis melakukan wawancara secara langsung dengan saudara Tjetjep Sudrajat, SE kepala sub bagian pendidikan dan penelitian sebagai stakeholder mengenai sistem yang digunakan pada rumah sakit tersebut. Dengan mengajukan beberapa pertanyaan lisan untuk melengkapi data-data yang ingin diperoleh. Wawancara dilakukan setiap penulis memerlukan data. Hal ini dilakukan agar penulis memperoleh data yang akurat.

\subsection{Metode Studi Pustaka (Studi Literature)}

Metode studi pustaka ini dilakukan sebagai penunjang dari hasil observasi dan wawancara yang telah dilakukan. Pengumpulan data yang dilakukan dengan mencari referensi-referensi yang berhubungan dengan judul penelitian. 


\section{Literature Review}

Banyak penelitian yang sebelumnya dilakukan mengenai sistem rawat inap dari penelitian lain yang berkaitan. Dalam upaya mengembangkan dan menyempurnakan sistem tersebut diperlukan studi pustaka (literature review) sebagai salah satu dari penerapan metode penelitian yang dilakukan diantaranya yaitu:

1. Penelitian ini dilakukan oleh Dian Gustiana (2018), yang berjudul ANALISA DAN PERANCANGAN SISTEM INFORMASI PENDAFTARAN PASIEN RAWAT JALAN PADA RUMAH SAKIT RAWAMANGUN. Penelitian ini membahas mengenai pengolahan data pasien yang melakukan rawat jalan masih dilakukan secara manual, sehingga perlu adanya sistem agar kebutuhan informasi lebih cepat dan akurat, menggunakan PHP sebagai bahasa yang mendukung pemograman dan MySQL sebagai database.

2. Penelitian ini dilakukan oleh Suriaman Gulo (2018), yang berjudul PERANCANGAN SISTEM INFORMASI ADMINISTRASI RAWAT INAP DAN RAWAT JALAN PADA RUMAH SAKIT UMUM SITI HAJAR. Penelitian ini membahas pengolahan data rawat inap dan rawat jalan yang masih menggunakan pembukuan yang bersifat manual, sehingga dirancanglah sebuah aplikasi yang dapat membantu rumah sakit khususnya bagian administrasi rawat inap dan rawat jalan, agar mempercepat proses penyajian informasi dan menghindari kesalahan dalam menghitung biaya rawat inap dan rawat jalan, serta mempermudah utuk menghasilkan sebuah laporan.

3. Penelitian ini dilakukan oleh Yuni Sugiarti (2015) yang berjudul ANALISA DAN PERANCANGAN SISTEM INFORMASI RAWAT INAP (STUDI KASUS RUMAH SAKIT IBU DAN ANAK BUAH HATI CIPUTAT). Penelitian ini membahas perancangan sistem pengolahan data pasien yang terjaga dan terintegrasi. Membantu dalam pendaftaran pasien untuk menentukan status kamar inap, proses pencarian data pasien dan pembuatan laporan. Sistem rawat inap dibangun dengan menggunakan bahasa pemograman PHP 5.1 dan MySQL database. Hasilnya sistem rawat inap yang terintegrasi dengan baik

Dari ketiga literature review yang ada, telah banyak penelitian mengenai rawat inap yang dilakukan dengan berbagai macam metode. Namun metode tersebut lebih terpusat kepada administrasi rawat inap. Tidak sampai dengan hasil diagnose pasien, tindakan yang didapat selama dirawat yg dapat dengan mudah dilakukan.

\section{Hasil Dan Pembahasan}

Untuk dapat menggambarkan prosedur secara keseluruhan diperlukan beberapa tahapan analisa sebagai bentuk pengumpulan informasi guna mendapatkan model yang sesuai dengan kebutuhan dan mampu memberikan solusi dengan cepat secara efektif dan efisien, mulai dari tahapan pengumpulan informasi dan kebutuhan, analisa dokumen, merancangan hubungan antar dokumen sampai dengan merancanga model diagram database dan model rancangan sistem. Beberapa tahapan yang dimaksud sampai dengan model ranangan yang diciptakan dapat dilihat pada gambar berikut : 


\section{Use Case Diagram Prosedur Berjalan}

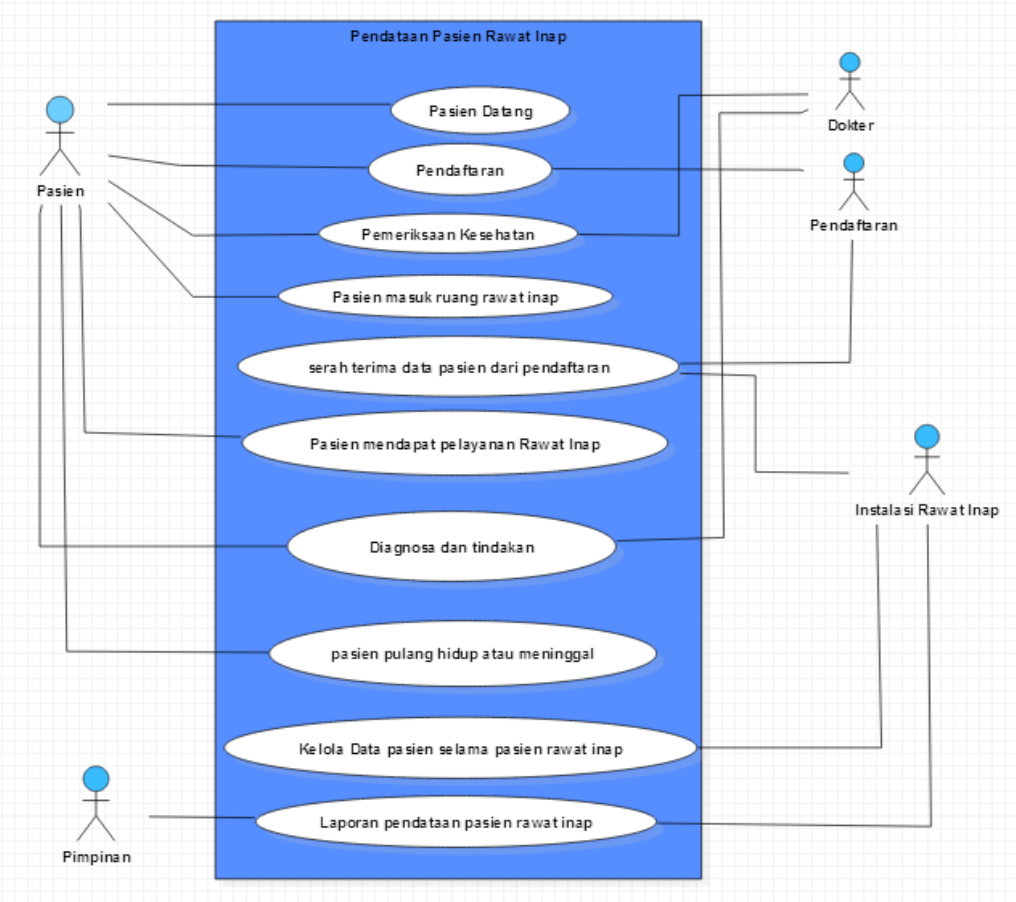

Gambar 1 Usecase Diagram

Berdasarkan gambar use case Diagram (gambar 1) yang berjalan saat ini sistem yang mencakup seluruh kegiatan pada sistem pendataan pasien rawat inap. Terdapat 1 (Satu) sistem pendataan pasien rawat inap yang mencangup seluruh kegiatan mulai dari Pasien datang sampai kegiatan laporan pendataan pasien rawat inap kepada pimpinan, 5 (Lima) Actor yang melakukan kegiatannya : Pasien, Pendaftaran, Dokter, Instalasi Rawat Inap dan Pimpinan.

Terdapat juga 10 (Sepuluh) Use Case yang merupakan proses yang terjadi pada sistem berjalan yaitu pasien datang, pasien melakukan pendaftaran melibatkan petugas pendaftaran, pemeriksaan kesehatan melibatkan dokter yang bertugas, pasien masuk ruang rawat inap, serah terima data pasien dari pendaftaran, pasien mendapatkan pelayanan rawat inap, pasien mendapatkan diagnose dan tindakan melibatkan dokter, pasien pulang hidup/meninggal, kelola data pasien selama pasien dirawat melibatkan instalasi rawat inap, laporan pendataan pasien rawat inap melibatkan pimpinan. 


\section{Squence Diagram Prosedur Berjalan}

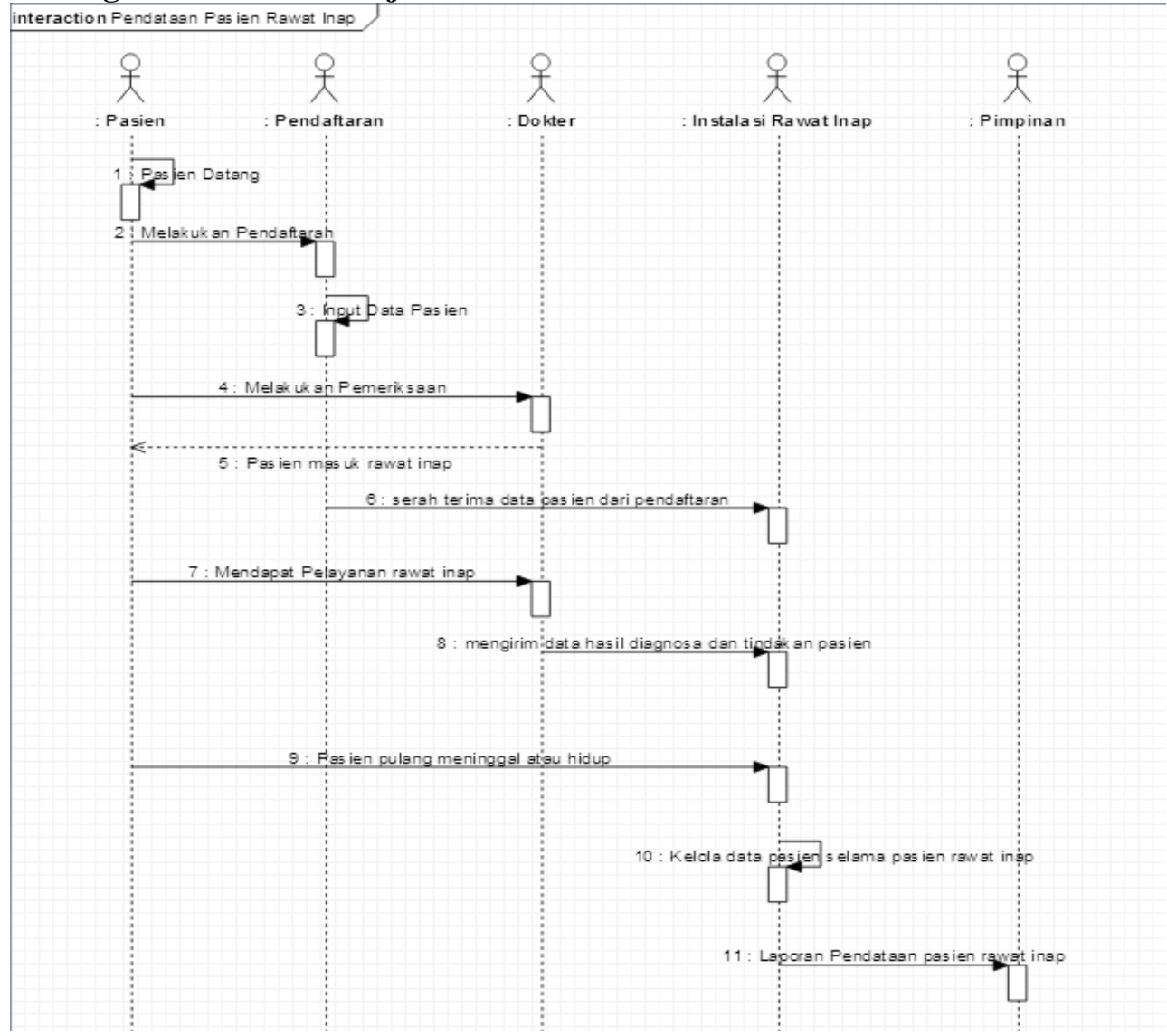

Gambar 2 Sequence Diagram

Berdasarkan gambar sequence diagram (gambar 2 ) yang berjalan saat ini terliha 5 (Lima) Actor yang melakukan kegiatan diantaranya: Pasien, Pendaftaran, Dokter, Instalasi Rawat Inap, Pimpinan, yang akan menyelesaikan 11 (Sebelas) Message Spesifikasi dari komunikasi antar objek yang memuatin formasi-informasi tentang aktifitas yang terjadi, yaitu pasien datang, melakukan pendaftaran, input data pasien, melakukan pemeriksaan, pasien masuk rawat inap, serah terima data pasien dari pendaftaran, mendapat pelayanan rawat inap, mengirim data hasil diagnose dan tindakan medis pasien, pasien pulang meninggal atau hidup, kelola data pasien selama pasien rawat inap, laporan pendataan pasien rawat inap. 


\section{Activity Diagram Prosedur Berjalan}

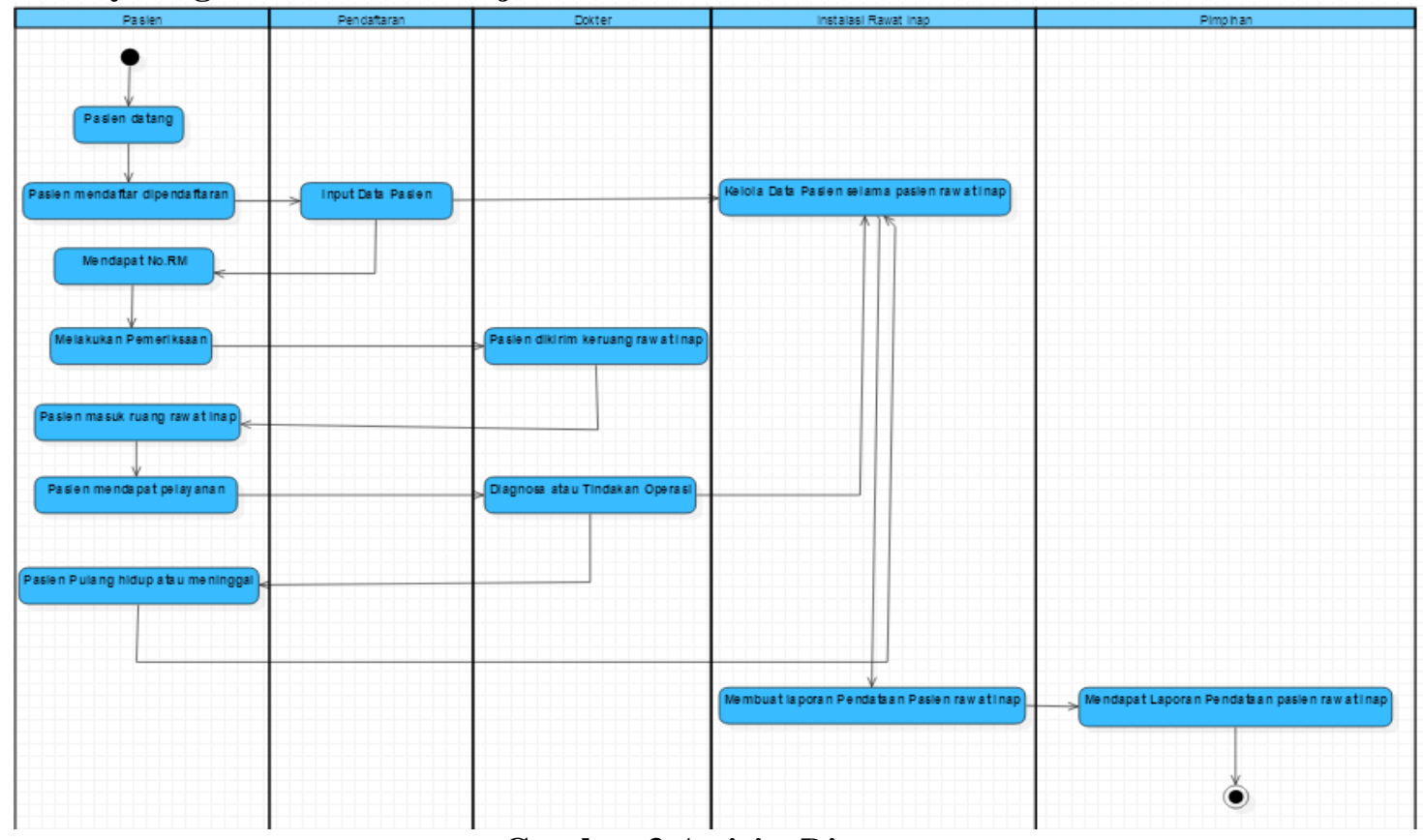

\section{Gambar 3 Activity Diagram}

Berdasarkan gambar activity diagram (gambar 3 ) yang berjalan saat ini sistem mencakup seluruh kegiatan pendataan pasien rawat inap. Sistem ini melibatkan 1 Initial Node untuk memulai suatu kegiatan, 5 Vertical Swimeline yaitu Pasien, Pendaftaran, Dokter, Instalasi Rawat Inap, Pimpinan, 13 Activity yang biasa dilakukan oleh actor-actor.

Rancangan diatas (gambar 1, 2, 3) merupakan gambaran prosedur yang berjalan dimana pada tahapan ini melibatkan beberapa dokumen form pendaftaran. Dimana form tersebut akan didata oleh petugas pendaftaran yang akan menghasilkan hasil diagnose dari dokter setelah melakukan pemeriksaan kesehatan.

\section{Class Diagram}

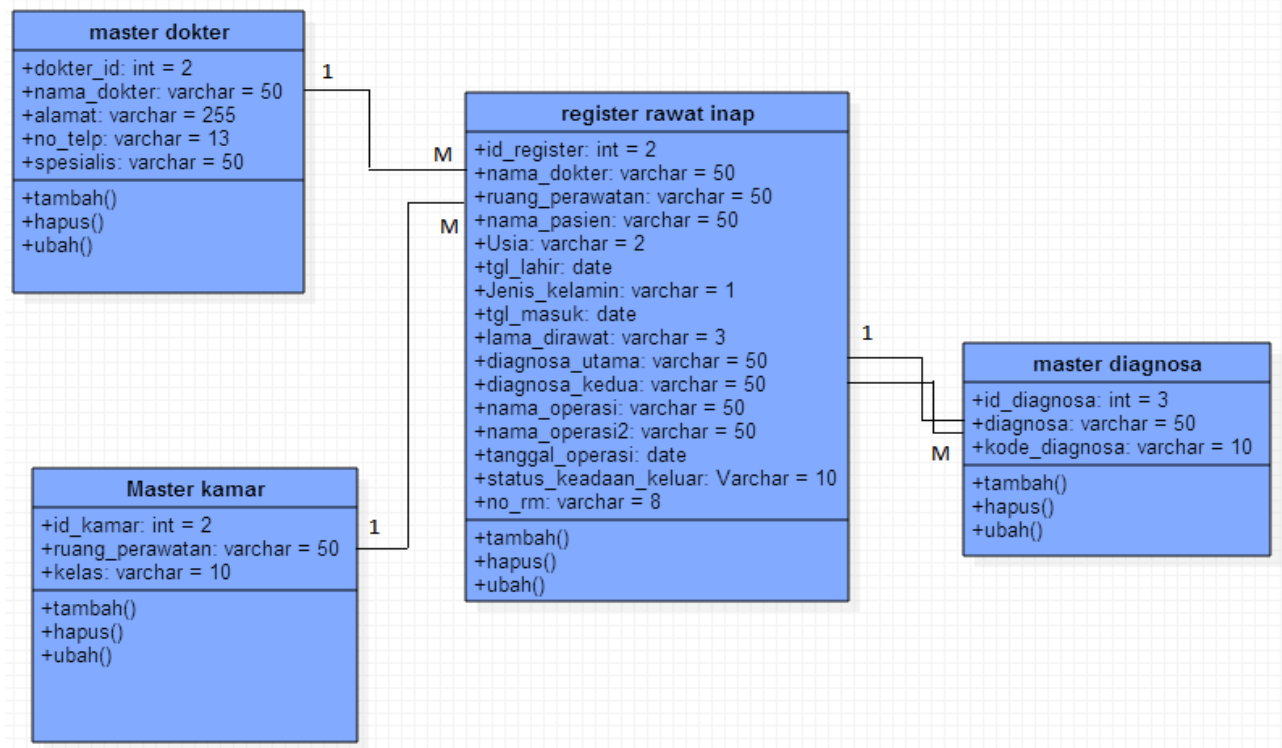

Gambar 4 Class Diagram 
Berdasarkan gambar class diagram (gambar 4) yang berjalan saat ini sistem yang mencakup seluruh kegiatan pada sistem pendataan pasien rawat inap. Terdapat 4 (empat) class yaitu registrasi rawat inap, master dokter, master kamar, master diagnose. Berdasarkan gambar class diagram (gambar 4) diatas dapat dilihat dengan jelas bahwa tingkat hubungan master dokter dan register rawat inap yaitu one to many (1:M), tingkat hubungan master kamar dan register rawat inap yaitu one to many (1:M), tingkat hubungan master diagnose dan register rawat inap yaitu many to one (M:I).

\section{Use Case Diagram Usulan}

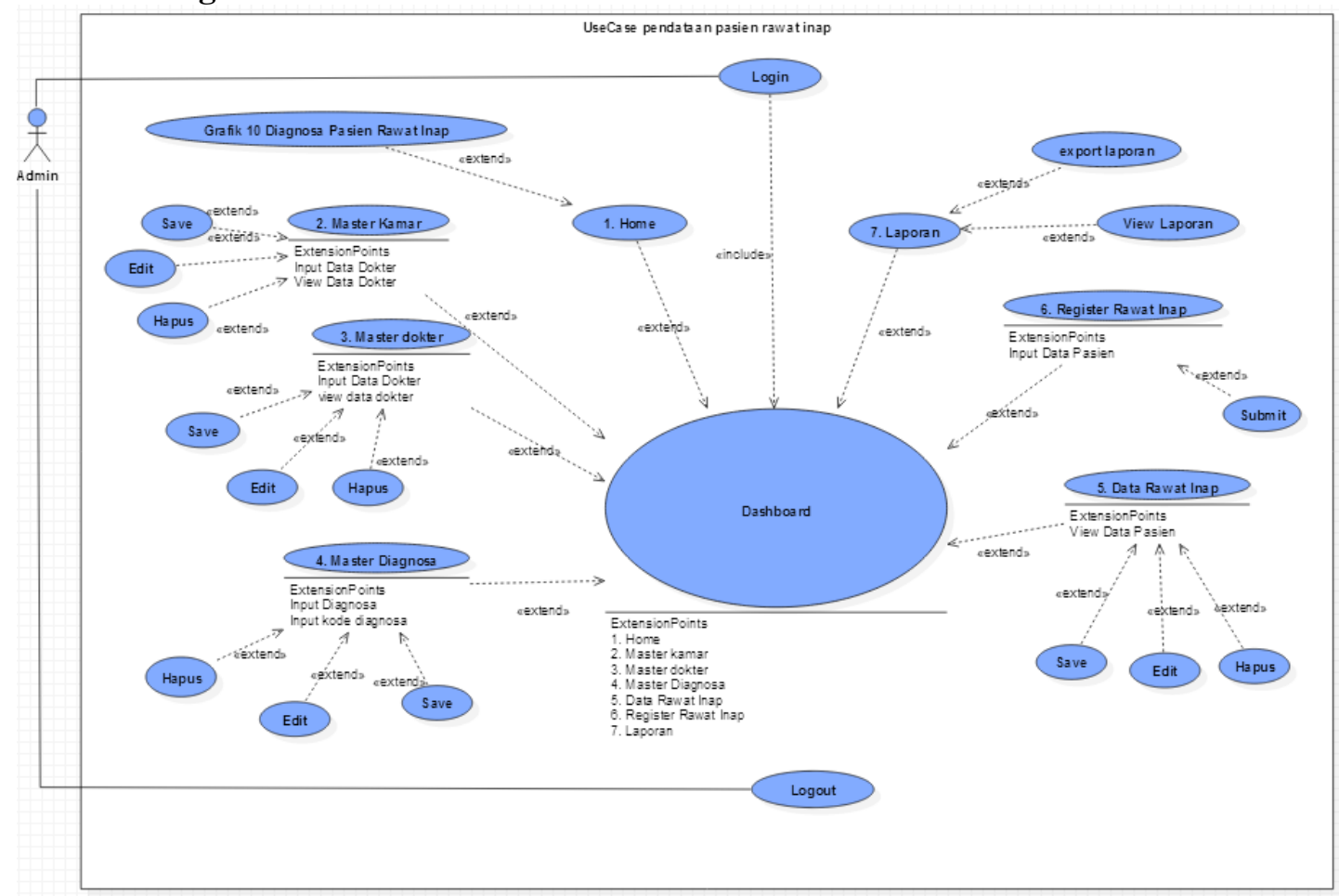

Gambar 5. Use Case Diagram

Berdasarkan gambar use case diagram usulan (gambar 5) terlihat jelas bahwa terdapat 26 use case yang terdiri dari 1 use case utama yaitu Dashboard, dari use case dashboard terdapat beberapa use case diantaranya home, master kamar, master dokter, master diagnose, register rawat inap, data rawat inap, laporan. Use case home, memiliki 1 (satu) yang terdiri dari grafik diagnose rawat inap, use case master kamar, master dokter, master diagnose dan data rawat inap sama-sama memiliki 3 (tiga) yang terdiri dari menu save, edit dan hapus. Use case register rawat iniap memiliki 1 (satu) yang terdiri dari menu submit. Use case laporan memiliki 2 (dua) yang terdiri dari export laporan dan view laporan.

Use case diagram sebagai bentuk rancangan sistem yang akan diciptakan (gambar 5) merupakan desain model tampilan utama yang berorientasi pada kebutuhan menu aplikasi yang disiapkan, selain itu untuk kebutuhan penyimpanan informasi data agar dapat digunakan secara histori juga digambarkan dalam bentuk class diagram (gambar 4) lengkap dengan informasi field dan type data sesuai kebutuhan penyimpanan data. Serta use case login yang merupakan akses awal untuk masuk ke dalam sebuah sistem berdasarkan informasi data username dan password

\section{Rancangan Tampilan}

Tampilan Sistem Pendataan Pasien Rawat Inap memiliki berbagai fitur rancangan yang digunakan untuk mencetak data dan mengirim data : 


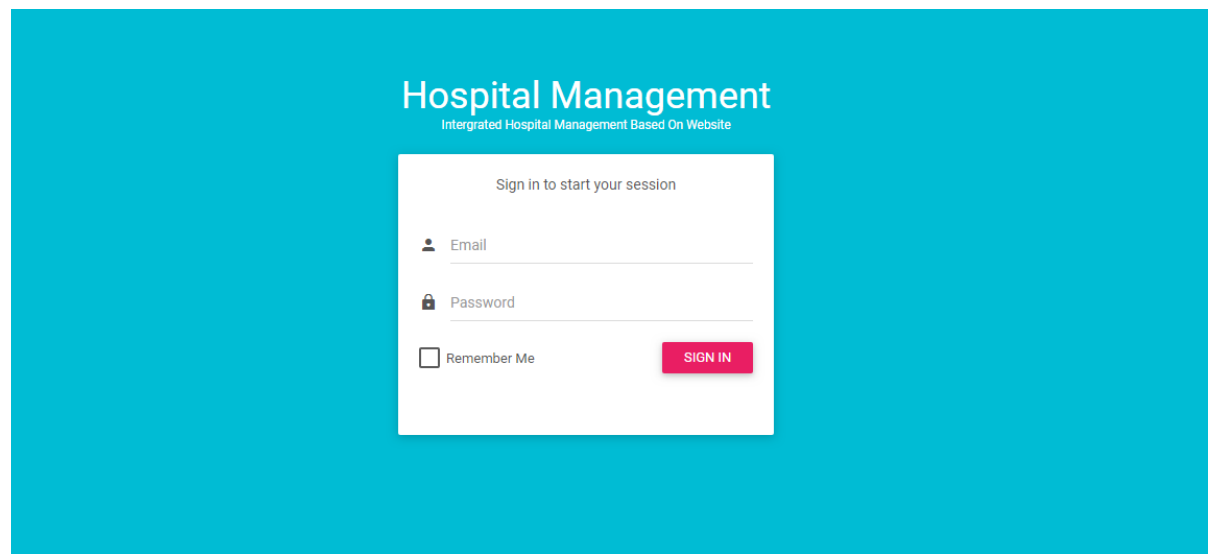

Gambar 6 Tampilan Halaman Login

User dengan benar selanjutnya klik login dan setelah itu user dapat masuk kedalam sistem. Sedangkan kalau username dan password salah maka tidak akan dapat masuk kedalam sistem dan akan muncul tulisan bahwa username dan password yang anda masukan salah.

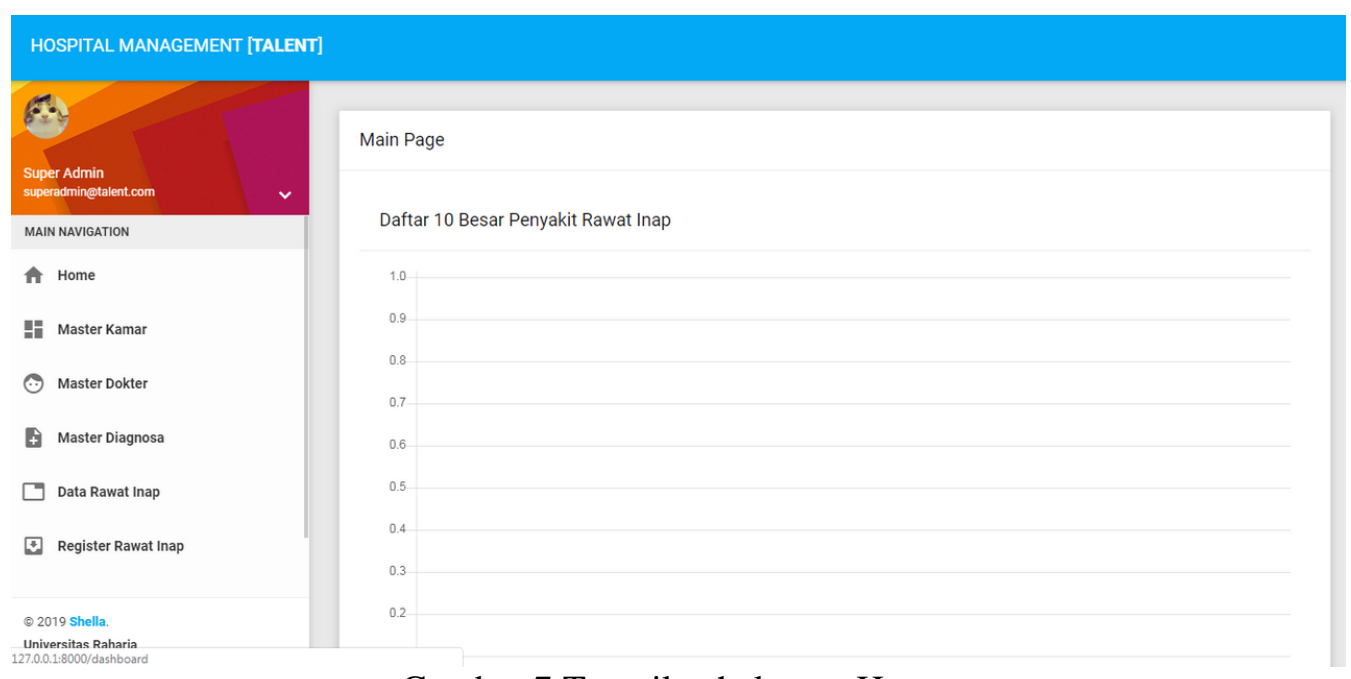

Gambar 7 Tampilan halaman Home

Tampilan yang akan muncul jika sudah memalukan login.

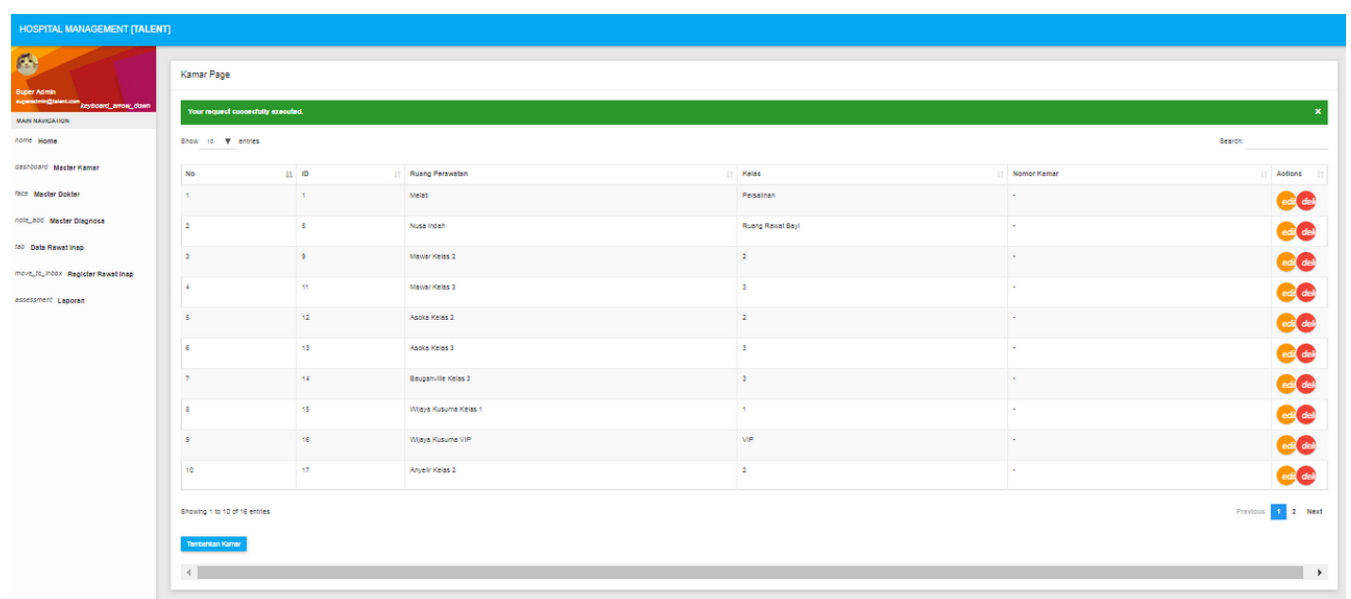

Gambar 8 Tampilan halaman data kamar 
Halaman ini berfungsi untuk menampilkan data pasien, ruang perawatan, kelas dan nomor kamar.

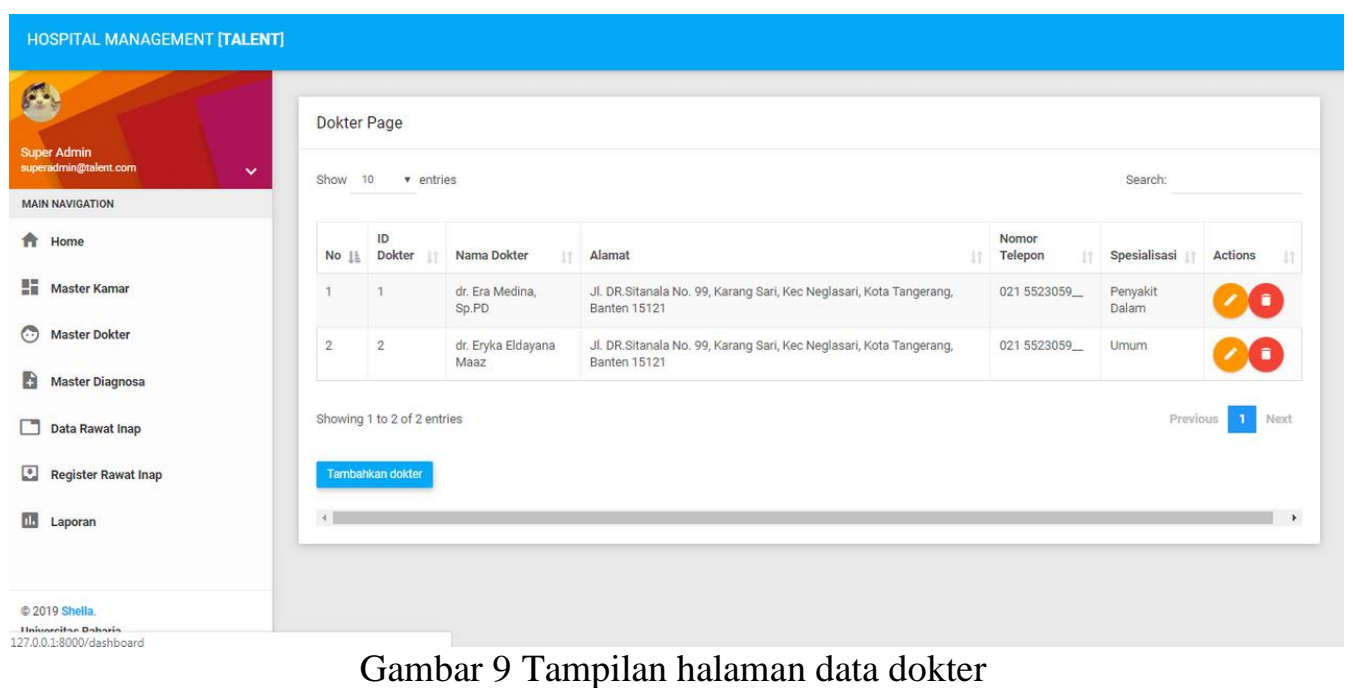

Halaman ini berfungsi untuk menampilkan data dokter meliputi nama dokter, alamat, nomor telepon, dan spesialisasi.

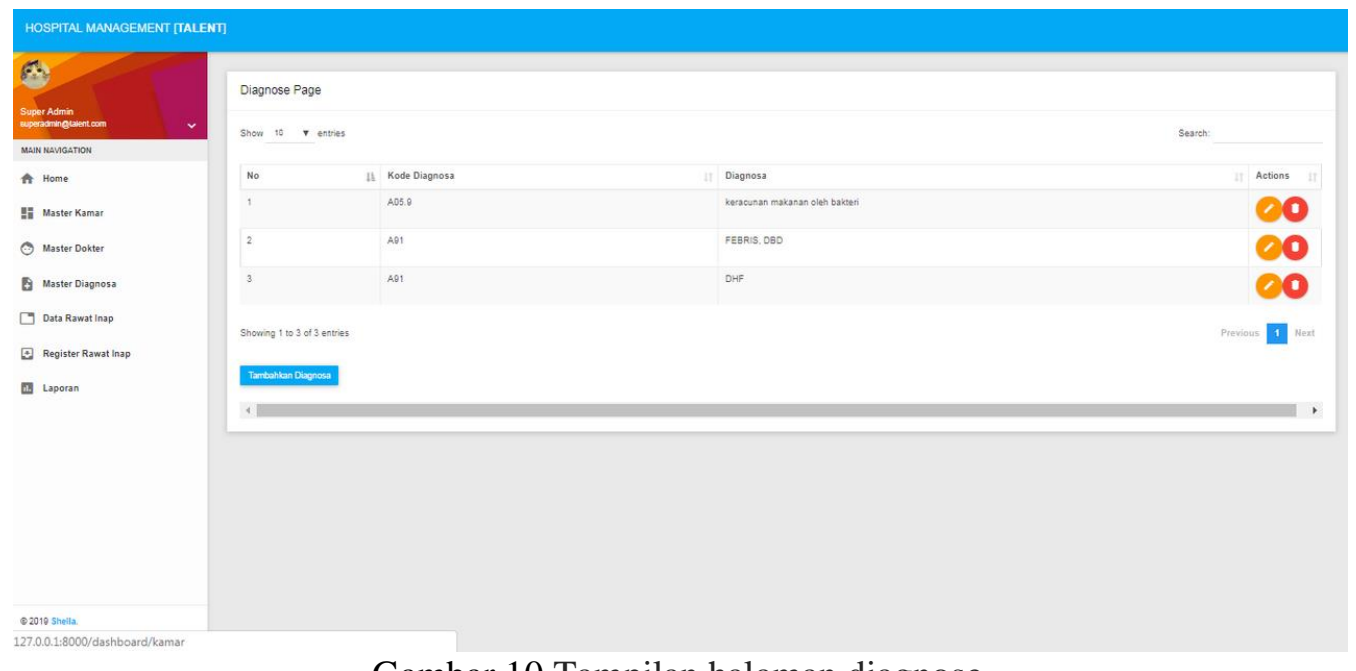

Gambar 10 Tampilan halaman diagnose

Halaman ini berfungsi untuk menampilkan data kode diagnose dan hasil diagnose 


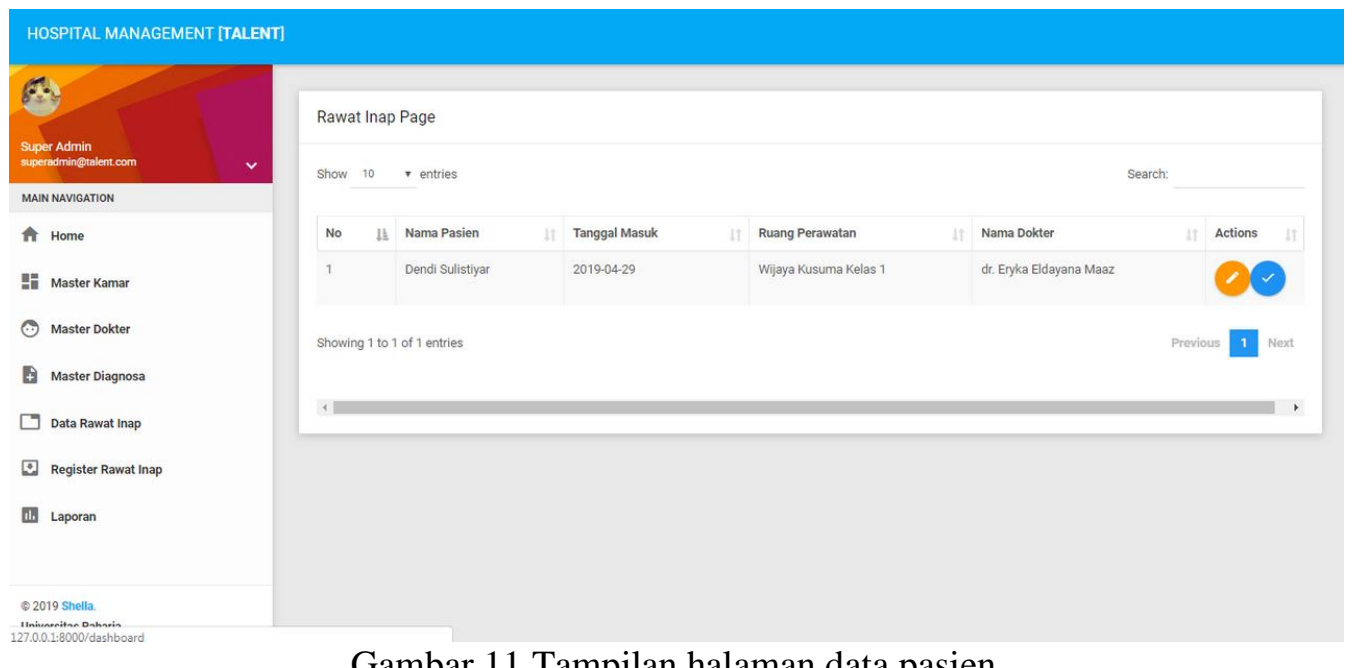

Gambar 11 Tampilan halaman data pasien

Halaman ini berfungsi untuk menampilkan data pasien meliputi nama pasien, tanggal masuk, ruang perawatan, dan nama dokter.

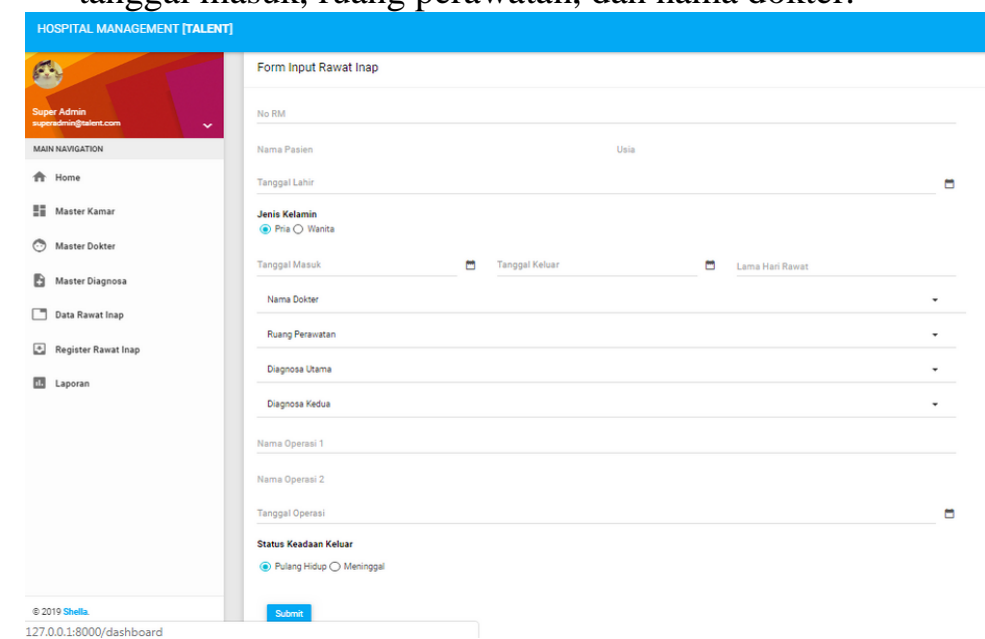

Gambar 12 Tampilan halaman register rawat inap

Halaman ini berfungsi untuk menampilkan data register yang harus di isi oleh pasien ketika mendaftar pada petugas.

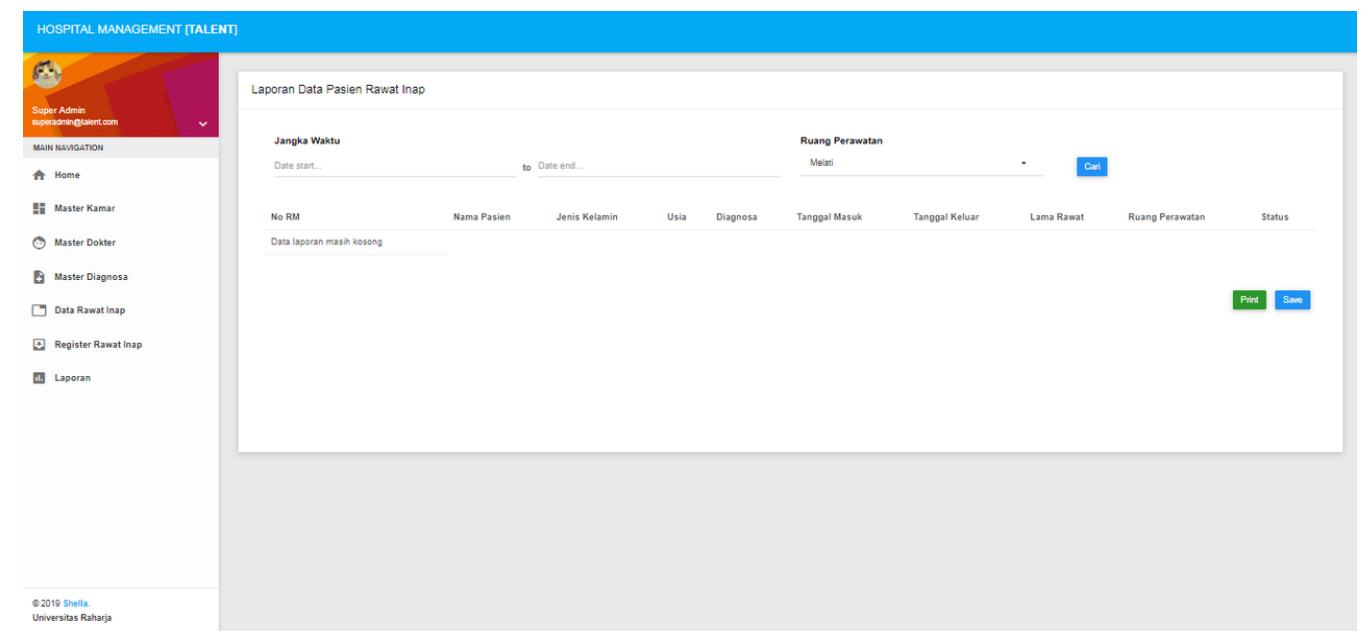

Gambar 13 Tampilan halaman laporan 
Apabila semua prosedur telah selesai dilakukan, maka selesai sudah penanganan Laporan pendataan pasien rawat inap

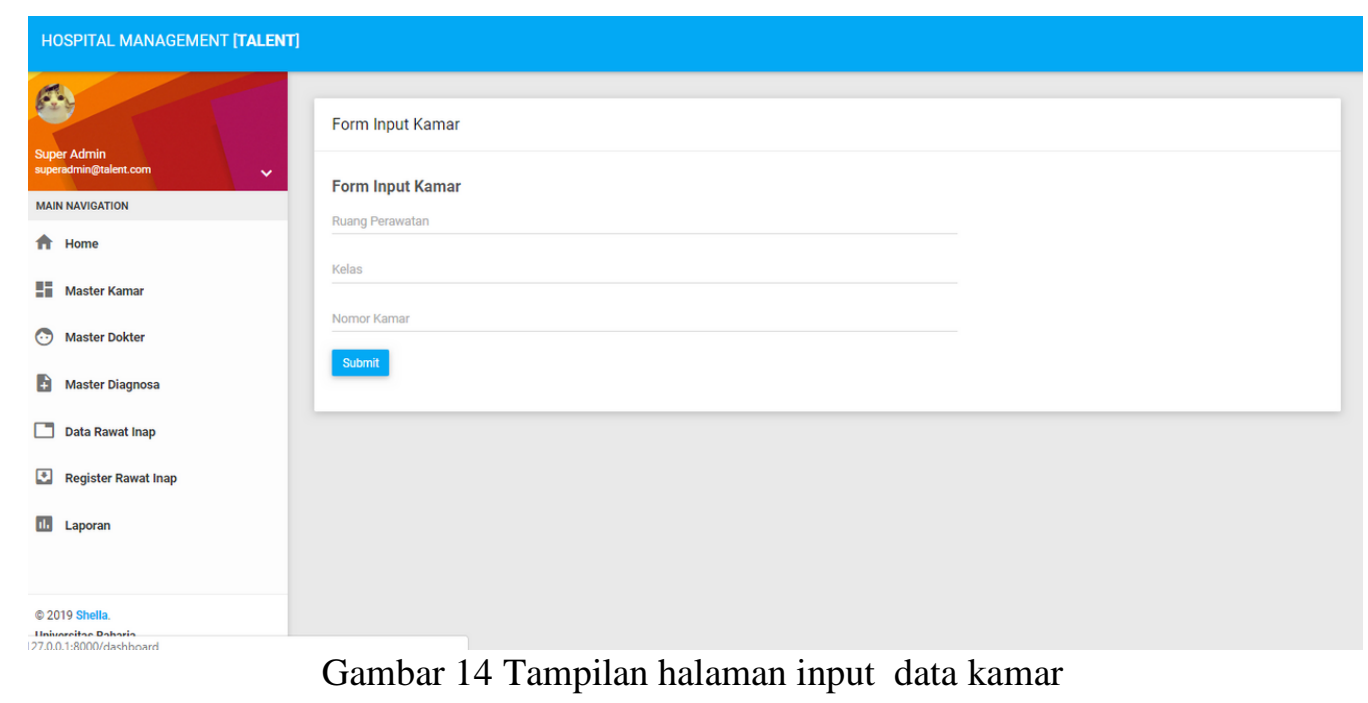

Halaman ini berfungsi untuk menampilkan form input data kamar pasien.

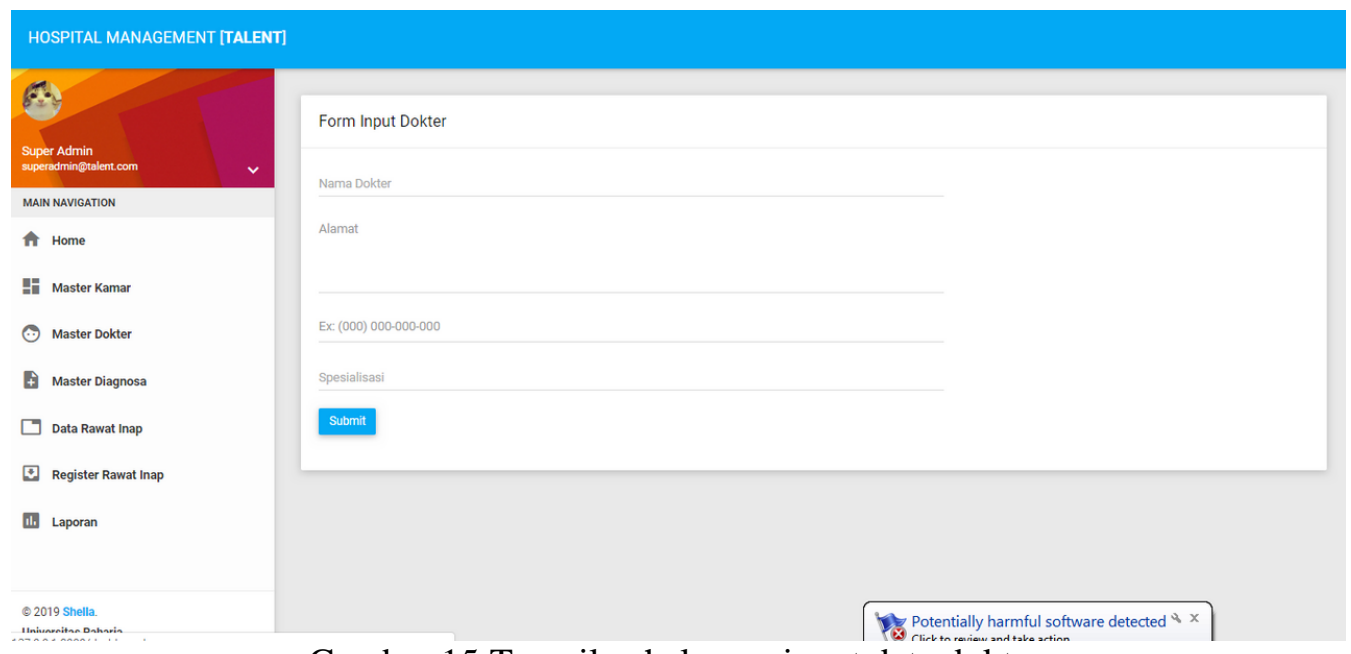

Gambar 15 Tampilan halaman input data dokter

Halaman ini berfungsi untuk menampilkan form input data dosen 


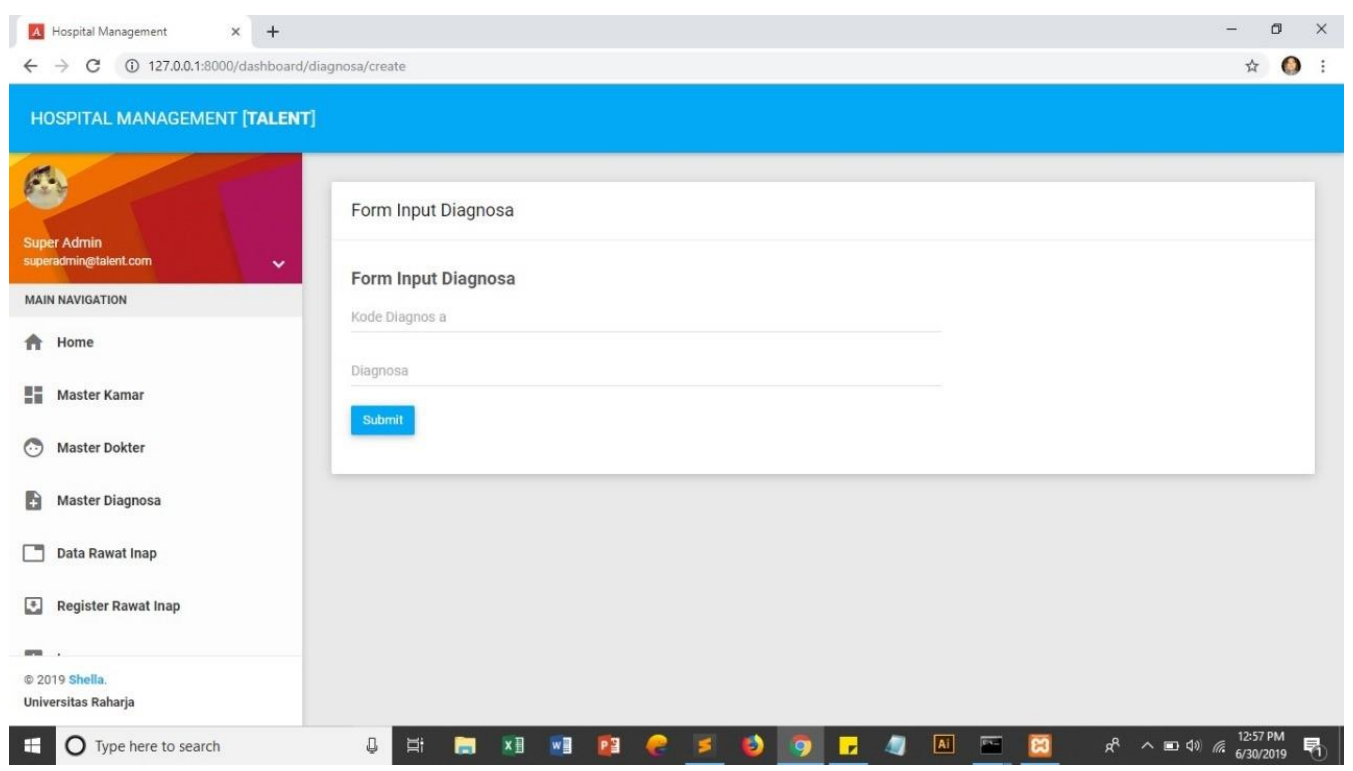

Gambar 16 Tampilan halaman input data diagnose pasien

Halaman ini berfungsi untuk menampilkan form input diagnose hasil pemeriksaan

\section{Kesimpulan}

Berdasarkan hasil analisa dan penelitian yang dilakukan, dapat disimpulkan bahwa Sistem pendatan pasien rawat inap yang sedang berjalan saat ini pada Rumah Sakit Sitanala masih manual, yaitu masih menggunakan Ms. Excel dalam melakukan pendataan pasien rawat inap, hal ini cukup memakan waktu dalam perhitungan sehingga tidak efektif dan efisien selain itu hasil kurang akurat. Dengan model yang dibuat diharapkan pendatan pasien rawat inap dapat dilakukan dengan cepat, akurat, obyektif dan transparan karena proses pendataan dilakukan secara komputerisasi untuk menentukan data pasien rawat inap. Selain itu adanya dashboard dalam bentuk rekapitulasi dapat dijadikan dasar pengambilan keputusan.

\section{Daftar Pustaka}

[1] Keputusan Menteri Kesehatan Republik Indonesia No. 1204/Menkes/SK/X/2004

[2] Peraturan Menteri Kesehatan Republik Indonesia No. 340/MENKES/PER/III/2010

[3] Gustiana, Dian, Ruri Puji Novianti. 2018. Analisa dan Perancangan Sistem Informasi Pendaftaran Pasien Rawat Jalan Berbasis Web pada Rumah Sakit Rawamangun. Jurnal Sistem Informasi Universitas Suryadarma 5 (2)

[4] Gulo, Suriaman, Roni Jhonson Simamora. 2018. Perancangan Sistem Informasi Administrasi Rawat Inap dan Rawat Jalan Pada Rumah Sakit Umum Siti Hajar. METHOMIKA: Jurnal Manajemen Informatika \& Komputerisasi Akutansi 2 (1), 30-42, 2018

[5] Sugiarti, Yuni, Nuryasin dan Nur Fitriani. 2015. "Analisis dan Perancangan Sistem Informasi Rawat Inap (Studi Kasus: Rumah Sakit Ibu dan Anak Buah Hati Ciputat). STUDIA INFORMATIKA: JURNAL SISTEM INFORMASI 8 (2), 2015 